Recebido em: 20/08/2020. Aprovado em: 30/11/2020.

Processo de Avaliação: Double Blind Review - SEER/OJS

e-ISSN: $2359-5876$

DOI: https://doi.org/10.48075/comsus.v7i3.26311

\title{
Cavalo dado se olha os dentes sim! Proposta de escalonamento da bolsa permanência à
} luz da vulnerabilidade

\section{Beggars can be choosers! Proposal for the staggering of the stock exchange permanence in the light of vulnerability}

\section{Resumo}

Renato Fabiano Cintra ${ }^{1}$

Gabriel Viana de Souza ${ }^{2}$

Helder de Lima Fava ${ }^{3}$

As políticas públicas de assistência estudantil possibilitam o acesso e a permanência dos estudantes em vulnerabilidade socioeconômica no ensino superior, como forma de diminuir as desigualdades sociais existentes no país. O Programa Nacional de Assistência Estudantil (PNAES) foi criado em 2010 e tem sido um referencial para as ações nesse âmbito de atuação, tanto no fornecimento de valores financeiros quanto nas diversas atividades realizadas pelas instituições federais de ensino superior brasileira. Neste sentido, este relato técnico apresenta uma proposta de escalonamento da bolsa permanência, a partir dos critérios de vulnerabilidade definidos no processo de avaliação socioeconômica. Os dados apresentados e analisados são de uma instituição federal de ensino superior da região Centro-Oeste do país. Os resultados apontam a possibilidade de escalonar os valores recebidos por cada estudante, como forma de propiciar melhora no índice de permanência e de conclusão dos assistidos, os quais compreendem os objetivos das políticas públicas, especialmente a do PNAES, bem como a adequação financeira frente aos orçamentos, cada vez mais limitado. As pesquisas acerca dessa temática corroboram a importância e a necessidade de valorizar e aprimorar os processos relacionados à assistência estudantil.

Palavras-chave: Assistência Estudantil; Vulnerabilidade; Permanência; Igualdade Social.

\section{Abstract}

The public policies of student assistance enable access and permanence of students in socioeconomic vulnerability in higher education, as a way of reducing social inequalities existing in the country. The National Student Assistance Program (PNAES) was created in 2010 and has been a benchmark for actions in this area of activity, both in terms of financial values and activities carried out by Brazilian federal higher education institutions. In this sense, this technical report presents a proposal for the staggering of the permanent scholarship, based on the vulnerability criteria defined in the socioeconomic evaluation process. The data and taxes are from a federal institution of higher education in the Midwest region of the country. The results point to the possibility of staggering the values received by each student, as a way of providing in the index of permanence and completion of those assisted, they understand the objectives of public policies, especially that of PNAES, as well as financial adequacy in relation to limited budgets. Research on this topic corroborates the importance and the need to value and improve processes related to student assistance.

Keywords: Student Assistance; Vulnerability; Permanence; Social Equality.

Cite as: (APA) Cintra, R. F., Souza, G. V., Fava, H. L. (2020). Cavalo 'dado' se olha os dentes sim! Proposta de escalonamento da bolsa permanência à luz da vulnerabilidade. Revista Competitividade e Sustentabilidade, 7(3), 710-721.

\footnotetext{
${ }^{1}$ Universidade Federal da Grande Dourados - UFGD. Brasil. E-mail: renatocintra@hotmail.com

${ }^{2}$ Universidade Federal da Grande Dourados - UFGD. Brasil. E-mail: gabrielviana1983@gmail.com

${ }^{3}$ Universidade Estadual do Mato Grosso do Sul - UEMS. Brasil. E-mail: $\underline{\text { helderlf@gmail.com }}$
} 


\section{INTRODUÇÃO}

As condições de desigualdade social, determinadas pelos elevados níveis de pobreza, desigualdade de distribuição de renda e oportunidades de inclusão dificultam que os jovens em situações de vulnerabilidade social tenham acesso ao ensino superior (Del Giúdice, Loreto \& Azevedo, 2014). Os estudantes que apresentam vulnerabilidade social estão propícios a interromper ou desistir dos cursos de graduação, por não haverem políticas que promovam a continuidade (Lima, 2017). Os estudos acerca da vulnerabilidade social tiveram uma maior discussão nos últimos anos, no sentido de instrumentalizar a investigação acerca da realidade atual do mundo do trabalho (Pereira \& Almeida, 2015). A permanência de pessoas em situação de vulnerabilidade socioeconômica configura-se como um dos novos desafios que a educação superior contemporânea apresenta (Oliveira, 2017). A adoção de alternativas que fortaleçam a política pública de assistência estudantil vislumbra um melhor planejamento e desenvolvimento das ações no âmbito dessa temática (Brito, Costa \& Almeida, 2019).

As instituições de ensino superior devem visualizar a importância de ações na assistência estudantil como forma de compromisso com seus estudantes, de modo que adotem mecanismos que atendam às necessidades desse segmento, como forma de evitar, inclusive, repercussões não desejáveis na formação acadêmica dos estudantes (Garrido, 2012). Percebe-se, deste modo a necessidade de implementação e/ou aprimoramento das políticas existentes como forma de reduzir os disparates ocasionados pelas desigualdades sociais que tanto tem implicação na vida do estudante universitário. O Programa Nacional de Assistência Estudantil (PNAES) dispõe que serão atendidos prioritariamente estudantes oriundos da rede pública ou com renda familiar per capita de até 1,5 salários mínimo. Logo, as Instituições Federais de Ensino Superior (IFES) tentam criar os seus critérios e requisitos para acomodar a política de assistência estudantil e mensurar a vulnerabilidade dos estudantes, haja vista que o Decreto 7.234/2010 não estabeleceu nenhum parâmetro. A identificação dos principais caminhos de pesquisas realizadas após a implantação do decreto do PNAES é de extrema importância, pois permite uma garantia de sucesso ao programa, além de apresentar os resultados a partir dos objetivos do referido programa (Souza \& Cintra, 2020), inclusive como forma de averiguar o uso do gasto público e a maneira como ele vem sendo utilizado (Fava \& Cintra, 2020).

Logo, este relato técnico apresenta proposta de escalonamento da bolsa permanência, utilizando critérios de vulnerabilidade socioeconômica do estudante. Utilizou-se de dados secundários a partir da seleção dos bolsistas de permanência e do índice de classificação (IC) dos referidos estudantes de uma instituição federal de ensino superior no Centro-Oeste do Brasil, no período de 2018 até 2019. Considerando que estudantes mais vulneráveis tem menores chances de concluir os estudos, além de precisarem de assistência maior em detrimento dos demais do grupo, este relato técnico justifica-se, como alternativa no propósito de atender qualitativamente os estudantes desse benefício. Além disso, contribui em identificar e mapear o perfil dos alunos do bolsa permanência. Portanto, o relato técnico foi organizado em: (1) introdução; (2) referencial teórico acerca dos processos de assistência estudantil e definições de vulnerabilidade; (3) método da produção técnica; (4) contexto do relato técnico; (5) tipo de intervenção e mecanismos adotados; (6) análise e resultados obtidos; e (7) considerações finais. 
Cintra, R. F., Souza, G. V., Fava, H. L. (2020). Cavalo 'dado' se olha os dentes sim! Proposta de

\section{REFERENCIAL TEÓRICO}

\subsection{A Formulação do Conceito de Permanência na Legislação Brasileira pós $\mathbf{1 9 8 8}$}

Quando a sociedade produz excluídos, seja pela pobreza, violência, racismo, educação, ela está caracterizada como uma sociedade partida, conflitante, intolerante, preconceituosa e injusta; especificamente, a exclusão educacional apresenta inúmeros problemas, que vão desde impactos econômicos até perspectivas de vida (Sobrinho, 2010). A Constituição Federal de 1988, em seus artigos 205 e 206, aponta a educação como direito de todos e dever do Estado e da família, e como tal deve ser promovida e incentivada, permeando os princípios de que haja igualdade de condições para o acesso e permanência na escola (Brasil, 1988), princípio este reforçado no artigo 3o da Lei de Diretrizes e Bases da Educação Nacional (Brasil, 1996).

Nesse sentido, a assistência estudantil no Brasil eclodiu a partir dos movimentos sociais que lutavam pelo fim do regime militar, culminando na promulgação da CF de 88 , através das frentes políticas de debate à educação, propostas pelo Fórum Nacional de Pró-reitores de Assuntos Comunitários e Estudantis (FONAPRACE), ocorrido em 1988 e pela Associação Nacional dos Dirigentes das Instituições Federais de Ensino Superior (ANDIFES) (Martins, Silva \& Mauricio, 2019). O alto grau de disparidade social da sociedade brasileira é o elemento motivador acerca da temática e relevância da assistência estudantil (Lima, 2017; Bordim, Baggio, Cintra \& Ribeiro, 2019), além do pressuposto de que as políticas públicas destinadas a esse fim constituem mecanismos de intervenção do Estado como forma de assegurar a igualdade de condições para o acesso e permanência dos estudantes na educação superior (Souza \& Cintra, 2020; Fava \& Cintra, 2020).

A assistência estudantil vai além do ingresso do acadêmico de baixa renda no ensino superior (Bordim et al., 2019), pois configura-se como uma política que propõe responder àquelas demandas de estudantes em vulnerabilidade socioeconômica, cuja participação no ensino superior foi ampliada na perspectiva da inclusão social, produção de conhecimento, melhoria do desempenho acadêmico e consequentemente da qualidade de vida (Assis, Sanabio, Magaldi \& Machado, 2013), constituindo-se também de um mecanismo de direito social (Fava \& Cintra, 2020). Dentre as ações de assistências podem ser citadas: Programa Universidade para Todos (PROUNI), Programa de Apoio a Planos de Reestruturação e Expansão das Universidades Federais (REUNI), Programa Nacional de Assistência Estudantil (PNAES) (Araújo, 2013) e o Bolsa Permanência MEC (Oliveira \& Silva, 2018).

O PROUNI, anunciado como carro-chefe na democratização da educação superior brasileira proposta pela Reforma Universitária do governo Lula (Catani, Hey \& Gilioli, 2006), teve o intuito de possibilitar e incentivar o estudo e o acesso ao ensino superior por estudantes brasileiros de baixa renda, oriundos do ensino médio público ou bolsistas integrais das escolas particulares, através de bolsas integrais ou parciais no auxílio do pagamento das mensalidades nas universidades particulares (Saraiva \& Nunes, 2011).

O REUNI, instituído através do Decreto no 6.096, de 24 de abril de 2007, objetivou a criação de condições para ampliação do acesso e permanência no ensino superior, além de definir, na meta global, a elevação gradual da taxa de conclusão média dos cursos de graduação presenciais para 90\% (Brasil, 2007). Ressalta ainda a importância de propiciar, não somente a mobilização estudantil, mas também a ampliação de políticas de inclusão e assistência estudantil (Araújo \& Pinheiro, 2010). Acoplado a um conjunto de financiamento para as universidades que aderiram, o REUNI caracteriza-se como programa de reforma das IFES, limitado à previsão orçamentária concedida, sem garantia da efetividade, continuidade 
e cumprimento dos acordos iniciais (Borges \& Aquino, 2012).

A transformação do Programa Nacional de Assistência Estudantil (PNAES), em 2010, num Decreto presidencial, garantiu a liberação dos recursos direto às IFES, como forma de manutenção das políticas de assistência estudantil (Assis et al., 2013). Assinalado como um desdobramento do REUNI no que tange à base necessária da política à democratização do ensino superior (Santiago, 2014), o PNAES foi resultado de movimentos sociais e reivindicações do FONAPRACE, mantém os critérios de seleção dos beneficiados a encargo da IFES e orienta quais estudantes tem prioridade (Betzek, 2015). Apenas são inseridos no programa os alunos que atendam o requisito de serem oriundos da rede pública de educação básica ou renda familiar per capita de até um salário mínimo e meio (Brasil, 2010).

Os objetivos do PNAES correspondem à democratização das condições em prol da permanência dos estudantes no ensino superior, minimizar as desigualdades sociais, reduzir as taxas de retenção e evasão, além de contribuir a inclusão social através da educação (Brasil, 2010). A superação e minimização das desigualdades existentes e a elitização histórica do ensino superior através da educação constituem os princípios do PNAES (Back, 2018). As ações abrangidas pelo PNAES envolvem: moradia estudantil, alimentação, transporte, atenção à saúde, inclusão digital, cultura, esporte, creche, apoio pedagógico e acesso, participação e aprendizagem de estudantes com deficiência, transtornos globais do desenvolvimento e altas habilidades e superdotação (Brasil, 2010), ações estas destinadas à permanência e formação do estudante (Cintra, Ribeiro \& Costa, 2018).

O auxílio e garantia da permanência na educação superior pelos estudantes em vulnerabilidade, advindos com o PNAES, fez com que este programa permitisse a esses estudantes o acesso e a permanência, o que constitui uma função da política de assistência estudantil (Back, 2018). Não obstante, a Portaria no 389, de 9 de maio de 2013, criou o Programa Bolsa Permanência, cujo objetivos constituem: viabilização da permanência em cursos de graduação por estudantes em situação de vulnerabilidade socioeconômica, redução dos custos de manutenção de vagas ociosas ocasionadas pela evasão e promoção da democratização do acesso ao ensino superior (MEC, 2013). Este programa teve foco especial para os estudantes indígenas e quilombolas, o que o caracteriza, entre outros motivos, mais restritivo em relação ao PNAES, por exemplo (Oliveira \& Silva, 2018).

\subsection{A Definição de Vulnerabilidade e suas Vertentes no Âmbito da Assistência Estudantil}

Os estudos acerca da vulnerabilidade apontam a existência de uma área formada por setores pobres na busca de alternativas para inclusão ou por aqueles setores que perderam canais de inclusão e se tornam médios empobrecidos (Pereira \& Almeida, 2015). A definição de vulnerabilidade, nos dicionários de língua portuguesa, compreende o estado de vulnerável, como aquele lado fraco de um assunto ou questionamento, ou ainda pelo qual alguma pessoa pode ser atacada ou ferida (Del Giúdice, 2013).

O termo vulnerabilidade pode ser usado por grupos distintos e com significados diferentes (De León, 2006). A vulnerabilidade compreende as condições determinadas por fatores ou processos físicos, sociais, econômicos e ambientais que aumentam a suscetibilidade de uma comunidade ao impacto de riscos ou perigos (ISDR, 2004). Estes fatores sociais são aqueles relacionados aos níveis de bem-estar das pessoas, gênero, saúde, alfabetização, educação, paz, segurança, direitos humanos e equidade social (De León, 2006). Os motivos da vulnerabilidade compreendem: fatores institucionais políticos associados à legislação incomensurável; fatores econômicos, como a ausência e/ou carência de recursos econômicos em prol de medidas preventivas à pobreza, dependência econômica de produtos 
e negligência frente aos desastres econômicos; e fatores socioculturais, como falta de educação, tradições e deficiências em busca de níveis de bem-estar geral (De León, 2006). 0 debate acerca da vulnerabilidade do estudante reforça a ideia das dificuldades de permanência, conforme estudos de Oliveira (2017), Del Giúdice (2013) e Pereira e Almeida (2015). Outrossim, a desigualdade socioeconômica pode afetar diversos aspectos da vida do estudante (Assis et al., 2013).

A lógica da assistência estudantil, enquanto assistência social direcionada à setores específicos da população, especificamente àqueles de classes exploradas e destituídas de direitos, não pode ser restrita ao repasse de bolsas ou auxílios materiais diversos, mas afirmase, inegavelmente, a necessidade de ações dessa natureza em um ambiente diversamente social (Abreu, 2014). Em uma pesquisa realizada pelo FONAPRACE nos anos de 1997, 2004 e 2010, com o intuito de conhecer o perfil cultural e socioeconômico das IFES do país, $44 \%$ da população de estudantes pertencem à classe $C, D$ e $E$, reforçando a necessidade de que os serviços de assistência estudantil representam, em muitos casos, a principal alternativa como permanência e conclusão dos estudos (Garrido, 2012).

As políticas voltadas para a democratização do ensino superior a partir de 2003 não foram ainda suficientes para inclusão dos marginalizados socialmente, especialmente nos cursos com alta demanda, pois estes conferem maior possibilidade de mobilidade social (Paula, 2017). O relatório mais recente acerca do perfil socioeconômico dos estudantes de graduação das IFES, no ano de 2018, retrata que os programas de permanência desenvolvidos com ou sem o financiamento do PNAES são essenciais e fundamentais para que os estudantes mantenham o vínculo e possam concluir seus cursos (Andifes, 2019).

Del Giúdice, Loreto e Azevedo (2014) apontam que as variáveis socioeconômicas influenciam em todo processo acadêmico, em razão principalmente dos riscos econômicos pelo qual se expõe às famílias dos estudantes, que limitam a maior parte das pessoas das classes mais populares, o que é intensificado com as restrições orçamentárias das universidades públicas. As ações relacionadas à Assistência Estudantil não devem se limitar apenas ao combate à pobreza, em programas que forneçam condições de subsistência, mas principalmente é necessário atentar-se às outras formas de vulnerabilidade social (Assis et al., 2013).

O abandono nas universidades federais, especialmente naqueles cursos de maior demanda, é motivado pelos problemas financeiros e pela necessidade de trabalhar por parte dos estudantes, fato este agravado quando se pontua que a demanda por bolsas é maior do que a oferta (PAULA, 2017). A existência de uma distorção de natureza socioeconômica nos campus brasileiros somam-se à origem social e situação econômica familiar dos estudantes, o que determinam, de certo modo, a trajetória do estudante na educação superior (Ristoff, 2014).

\section{MÉTODO DA PRODUÇÃO TÉCNICA}

O presente Relatório Técnico teve como guia os editais de divulgação dos resultados do programa Bolsa Permanência de Assistência Estudantil do ano de 2018 e o Relatório Mensal de Pagamento de bolsas de janeiro de 2019. Compilado os dados em forma de tabela, o próximo passo foi enquadrar os estudantes que recebem o auxílio financeiro em extratos de 100 em 100, do menor IC para o maior, identificando a quantidade de indivíduos em cada estrato. Optou por estratificar de faixas de IC de 100 em 100, tendo em vista a praticidade e a quantidade de faixas que resultaram. Outra sugestão poderia ser de 50 em 50 (já teríamos 
grupos mais homogêneos e mais faixas) ou talvez de 150 em 150 (grupos mais heterogêneos e menos faixas). Talvez o que foi praticado aqui seja o meio termo: tendência a grupos mais homogêneos e menos faixas.

A ordem para classificação dos estudantes que concorrem à Bolsa permanência é determinada pelo índice de Classificação (IC), através do qual é realizada a medição e determinada a condição de vulnerabilidade do aluno. O IC leva em consideração a seguinte fórmula: IC= (RT/GF) x MR x TR x DG x EP x ET. O IC = Índice de Classificação; RT = Renda Bruta Total Mensal do Grupo Familiar; GF = Número de membros do Grupo Familiar incluindo o estudante; $M R=$ Índice redutor associado aos gastos com a moradia do Grupo Familiar (indicador de vulnerabilidade); TR = Índice redutor associado aos gastos com transporte (indicador de vulnerabilidade); DG = Índice redutor associado à existência de doença grave conforme especificada na Portaria MPAS-MS-2.998 (indicador de vulnerabilidade); EP = Índice redutor associado ao incentivo ao estudante proveniente de escola pública (indicador de vulnerabilidade); ET= Índice redutor associado ao incentivo ao estudante matriculado que apresenta atividade de trabalho com carga horária acima de 30h semanais (indicador de vulnerabilidade). Para MR: (a) $M R=1$, se a moradia é própria ou cedida; (b) $M R=1-0,4 x$ (gastos com moradia/RT), se a moradia for financiada ou alugada (nos gastos com moradia não se consideram gastos com luz, água, condomínio, internet e telefone). Para TR: (a) TR =1, se o Grupo Familiar possui condução própria; (b) TR = 1-0,4 x (gastos com transporte/RT), em outros casos. Para DG: (a) $D G=0,8$, se existe doença grave no grupo familiar conforme especificada na Portaria MPAS-MS-2.998-2001; (b) DG =1, se não existe doença grave no grupo familiar conforme especificada na Portaria MPAS-MS-2.998/2001. Para EP: (a) EP =0,6 se o estudante cursou integralmente o ensino médio em escola da rede pública ou escola particular com bolsa integral; (b) EP= 0,8 , se o estudante cursou escola particular com bolsa parcial ou escolas técnicas públicas; (c) EP = 1, em outros casos. Para ET temos: (a) ET=0,8, o estudante que apresenta atividade de trabalho com carga horária acima de 30 horas semanais; (b) ET=1, em outros casos.

A amostra de estudantes levantada foi de 1029 estudantes, sendo desconsiderados na sequência os indivíduos em duplicidade. Ao efetuar a exclusão dos estudantes repetidos a amostra utilizada para o estudo foi de 966 alunos. Quantificado o número de estudantes em cada faixa com os valores de IC, foi proposto um escalonamento dos valores das bolsas de acordo com as projeções que compreendem o impacto financeiro na instituição dentro dos parâmetros aceitáveis e das condições financeiras da Universidade. Ao escalonar do menor IC para o maior, ou seja, quanto menor o IC, maior será a indicação de vulnerabilidade do aluno, foi possível considerar o menor IC atendido pelo programa e verificar qual foi o maior índice de vulnerabilidade que foi atendido pelo programa.

\section{CONTEXTO DO RELATO TÉCNICO}

A instituição objeto de estudo é uma Instituição Federal de Ensino Superior situada no Centro Oeste, com mais de oito mil estudantes ativos, com orçamento anual que ultrapassa 200 milhões de reais no ano 2019. A Universidade é uma Fundação de direito público e não possui receita própria, mas depende de recursos do tesouro para o seu funcionamento. A Universidade atua na área do ensino, pesquisa e extensão e busca inovar conhecimentos e valores na formação de profissionais das diferentes áreas do conhecimento. A instituição conta com um quadro de mais de 1.500 servidores efetivos e mais de 15 anos de atuação. A Universidade é organizada em divisões administrativas que incluem os conselhos superiores, 
a unidade da administração central da Reitoria, as Pró-Reitorias, os órgãos administrativos e suplementares e as Faculdades. A assistência estudantil é responsabilidade da Pró-Reitoria de Assuntos Comunitários e Estudantis e tem status de Pró-Reitoria desde 2013.

\section{TIPO DE INTERVENÇÃO E MECANISMOS ADOTADOS}

A Intervenção a ser realizada descreve detalhadamente as atividades de concessão do programa de bolsas, analisando as diferentes classificações de vulnerabilidade dos assistidos e propõe uma solução implementável e replicável, pautada em dados e projeções, diagnosticando uma situação que pode ser aperfeiçoada na medida que beneficia os estudantes em condição de vulnerabilidade elevada e que necessitam de maior atenção por parte das ações de assistência estudantil. Assim, a referida premissa do relato parte da hipótese de que mesmos os estudantes de mesmo grupo e de classe social devem ter sua assistência baseada nas condições de vulnerabilidade. Em outras palavras e via de regra, os estudantes com maior vulnerabilidade socioeconômica devem ser os estudantes com maior assistência por parte das políticas de assistência estudantil.

\section{ANÁLISE E RESULTADOS OBTIDOS}

Ao fazer uma análise inicial dos resultados pode constar que a média do IC foi de 385,489. Dos 966 estudantes, 760 estudantes estavam ativos e 206 foram excluídos por algum motivo, tais como (mais frequentes): 70 alunos concluíram o curso (34,3\%); 48 alunos reprovaram por nota e/ou falta sem justificativa plausível (23,2\%); 13 alunos ultrapassaram dois semestres de integralização do tempo normal (6,3\%); e 11 alunos não tiveram carga horária mínima necessária e não justificaram a referida redução. Da amostra, 39,9\% são masculinos e $60,1 \%$ são femininos e $30 \%$ cursam graduação na modalidade um turno - parcial (manhã, tarde ou noite) e 69,5\% cursam graduação na modalidade integral (manhã e tarde).

Ao estratificar os estudantes do bolsa permanência em seus respectivos ICs, de 100 em 100 , do menor para o maior IC, identificou-se a quantidade de alunos em cada faixa de sua referida vulnerabilidade, tem-se a Figura 1. Quanto maior for o IC, menos vulnerável será o estudante, e quanto menor o IC, maior será a vulnerabilidade econômica. Depois de estruturada a classificação dos índices, percebe-se que o menor IC atendido pelo programa bolsa permanência foi de 6,580, enquanto o maior índice no auxílio foi de $1.182,025$, e que foi atendido pela Pró-Reitoria de Assuntos Comunitários e Estudantis. 
Figura 1. Estratos de vulnerabilidade dos estudantes do bolsa permanência

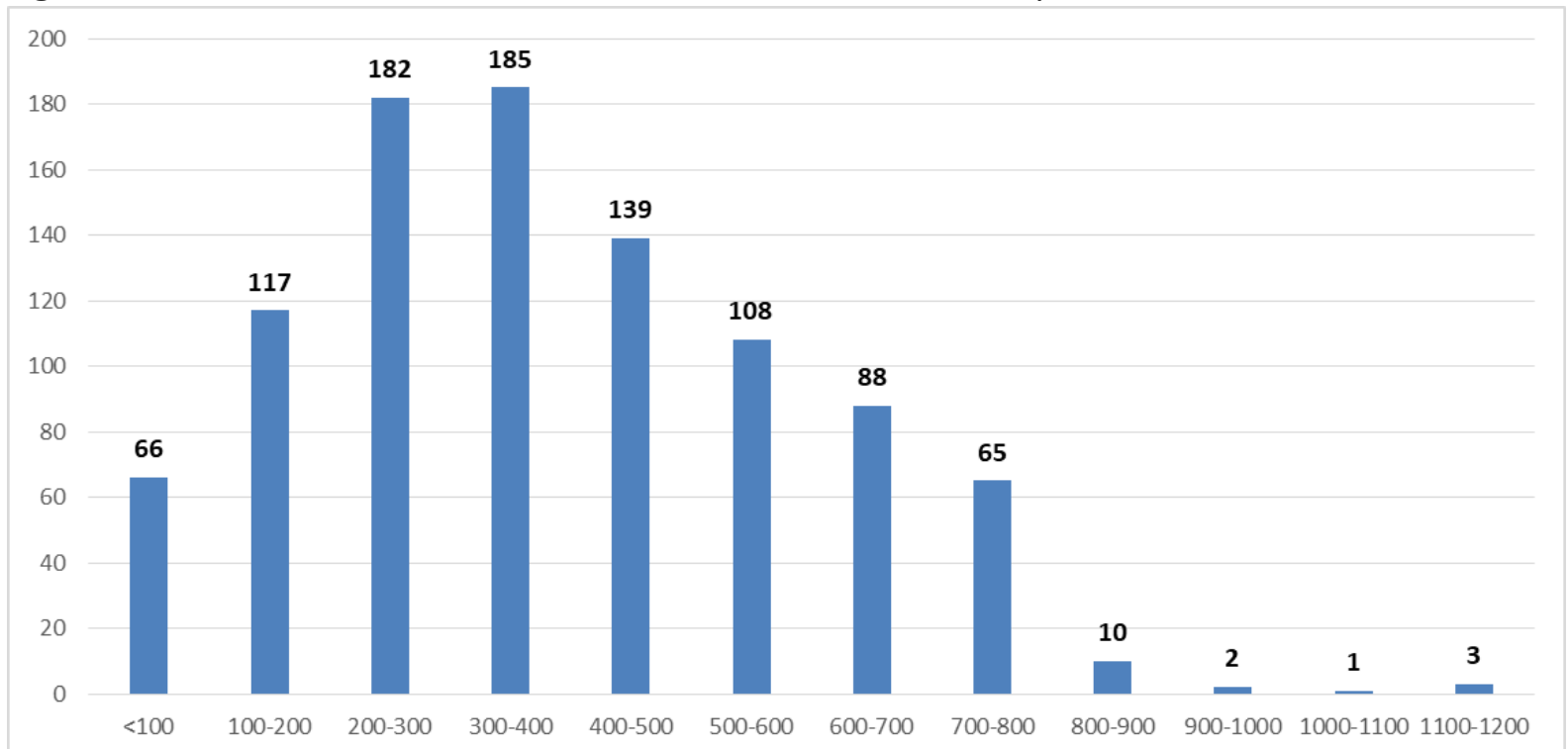

Fonte: Resultados do relato técnico.

Dentre a amostra dos 966 estudantes considerados, há uma quantidade menor de alunos que são enquadrados na primeira faixa, com IC menor que 100. Apenas 66 estudantes estão nesta faixa, seguido por 117 que estão entre 100 e 200. Com o IC na faixa entre 200 e 300 foram classificados 182 alunos, entre 300 e 400 foram 185. Acima de 400 temos um montante de 416 estudantes, que corresponde a $43 \%$ dos estudantes com bolsa. Assim, é possível notar que mais da metade dos estudantes assistidos possuem um grau maior de vulnerabilidade (média a alta), e estão sendo enquadrados igualmente na distribuição dos valores, o que contribuem em atenuar a vulnerabilidade, mas não afastam a totalmente.

Desta forma, foram feitas duas propostas no sentido de criar dois cenários (o primeiro com impacto de até $10 \%$ do gasto anual com o programa e o segundo com impacto de até $20 \%$ do gasto anual com o programa), haja vista que a instituição tinha um resto a pagar para o referido programa na casa de 800 mil reais. Em outras palavras, o referido impacto estaria garantido pelo menos para o primeiro ano de execução. Antes de adentrar na proposta, vale ressaltar que outras universidades já utilizam de sistemas de escalonamento de bolsas através de níveis de valores de acordo com a classificação do estudante, entre elas estão a Universidade Federal de Minas Gerais (UFMG), Universidade Federal Rural do Rio de Janeiro (UFRRJ), Universidade Federal de Fronteira do Sul (UFFS) e Universidade de Brasília (UNB).

Assim, as propostas de escalonamento para o programa de bolsa permanência levaria em consideração o IC de forma escalonada. A primeira proposta sugere aumento de $50 \%$ nos valores da bolsa para estudantes com o IC abaixo de 100, 25\% para os estudantes com IC entre 100 e $200,15 \%$ para os estudantes com IC entre 200 e 300, e nenhuma modificação nos valores para índices acima de 300. A segunda proposta consideraria aumento de $50 \%$ para os estudantes com o IC abaixo de 100,40\% para os estudantes com IC entre 100 e 200, 30\% para os estudantes com IC entre 200 e 300, 20\% para os estudantes com IC entre 300 e 400 e nenhuma modificação nos valores para índices acima de 400. A Tabela 1 demonstra o escalonamento das propostas: 
Tabela 1. Situação atual e propostas de escalonamento no bolsa permanência

\begin{tabular}{|c|c|c|c|c|c|}
\hline Índice & $\mathrm{IC}<100$ & Entre 100 e 200 & Entre 200 e 300 & Entre 300 e 400 & $\mathrm{IC}>400$ \\
\hline Atual & $\mathrm{R} \$ 400,00$ & $\mathrm{R} \$ 400,00$ & $\mathrm{R} \$ 400,00$ & $\mathrm{R} \$ 400,00$ & $\mathrm{R} \$ 400,00$ \\
\hline $\mathrm{P} 1$ & $\mathrm{R} \$ 600,00$ & $\mathrm{R} \$ 500,00$ & $\mathrm{R} \$ 460,00$ & $\mathrm{R} \$ 400,00$ & $\mathrm{R} \$ 400,00$ \\
\hline $\mathrm{P} 2$ & $\mathrm{R} \$ 600,00$ & $\mathrm{R} \$ 560,00$ & $\mathrm{R} \$ 520,00$ & $\mathrm{R} \$ 480,00$ & $\mathrm{R} \$ 400,00$ \\
\hline$\%$ & $\begin{array}{c}\text { Incremento de } \\
50 \%\end{array}$ & $\begin{array}{c}\text { Incremento de } \\
25 \% \text { até } 40 \%\end{array}$ & $\begin{array}{c}\text { Incremente de } \\
15 \% \text { a 30\% }\end{array}$ & $\begin{array}{c}\text { Incremento de } \\
0 \% \text { a } 20 \%\end{array}$ & $\begin{array}{c}\text { Nenhum } \\
\text { incremento }\end{array}$ \\
\hline
\end{tabular}

Fonte: Resultados do relato técnico.

O impacto financeiro que a primeira proposta de escalonamento das bolsas produziria seria de $\mathrm{R} \$ 35.820,00$ mensais, ou seja, $\mathrm{R} \$ 429.840,00$ no ano. O que seria de $9 \%$ dos valores gastos atualmente com o programa bolsa permanência anual (4,8 milhões de reais). A segunda proposta teria um impacto de $\mathrm{R} \$ \mathbf{6 8 . 5 6 0 , 0 0}$ mensais, ou seja, $\mathrm{R} \$ \mathbf{8 2 2 . 7 2 0 , 0 0}$ no ano. Este impacto seria de aproximadamente $18 \%$ do orçamento da disponível para a assistência estudantil na instituição em 2019.

Tal proposta de escalonamento seria estendido para o programa moradia estudantil, haja vista que o valor do benefício para quem reside na moradia estudantil corresponde a $50 \%$ do valor financeiro da bolsa permanência ( $R \$ 200,00)$. O impacto orçamentário seria de $\mathrm{R} \$ 1.390,00$ mensais, totalizando $\mathrm{R} \$ 16.680,00$ anuais. Este valor somado ao impacto da P1 seria de $\mathrm{R} \$ 446.520,00$ (9,3\% do valor gasto), enquanto que para a P2 o montante anual seria de $\mathrm{R} \$ 839.400,00$ (17,5\% do valor gasto), o que ainda assim seria um percentual factível de execução, não majorando nem $1 \%$ de impacto final.

Assim, a proposta de escalonamento aproxima o ponto de equilíbrio entre as proposições da política de assistência estudantil em responder às demandas dos estudantes que se apresentam em condições de vulnerabilidade econômica e a realidade fatídica que pressiona os indivíduos a buscarem outras alternativas à conclusão do ensino superior. Deste modo a ampliação da participação e da manutenção desta no ensino superior arregimenta-se em bases mais sólidas à produção do conhecimento, melhoria do desempenho acadêmico e conclusão do curso. O escalonamento foi pensado em consonância com o princípio da igualdade contido na constituição, ao propor tratar desigualmente os desiguais na medida de suas desigualdades.

Ao propor um escalonamento dos valores das bolsas em duas propostas, diferentes quanto ao percentual aplicado na majoração, e ainda uma proposta adicional de escalonamento das bolsas da Moradia Estudantil considerada nas duas propostas com os devidos valores de impacto orçamentário, o objetivo é equalizar uma balança que tende a pender para a divergência das condições de vulnerabilidade dos diferentes estudantes assistidos.

\section{CONSIDERAÇÕES FINAIS}

Ao analisar e refletir sobre os atuais moldes de concessão de bolsas dentro do programa de assistência estudantil, é necessário dispensar maior atenção ao grau de vulnerabilidade dos estudantes, que de acordo com a análise realizada pela Pró-Reitoria responsável pela concessão, independentemente das diferentes classificações dos IC, são contemplados com iguais valores de auxílio. Neste sentido, a proposta de escalonamento tende a equalizar de forma justa e responsável, dentro dos limites orçamentários disponíveis, o recebimento de valores que possibilitem a igualdade de condições e as melhorias na 
qualidade do desenvolvimento dos estudos dentro da Universidade, minimizando assim a vulnerabilidade do referido estudante. Em outras palavras, deve-se fazer uma reflexão acerca do benefício para que atinja uma maior quantidade de alunos, mas com a devida qualidade, promoção da emancipação e características individuais. O que se faz aqui é uma analogia ao ditado popular de que "cavalo dado não se olha os dentes", entretanto deve olhar sim os dentes, haja vista que o benefício é um direito enquanto política pública e visa corrigir desigualdades históricas que atingem os alunos vulneráveis de assistência estudantil em suas mais diversas situações.

Embora os níveis de bolsa correlacionado à condição de vulnerabilidade econômica do estudante assistido já sejam adotados em outras instituições públicas de ensino superior, a proposta de escalonamento contida neste Relatório Técnico é adequada ao referido contexto em estudo e apta a ser replicada em outras instituições. Não obstante seja de conhecimento público os termos do decreto $9.741 / 19$ sobre o contingenciamento de despesas do governo federal, e a diminuição em $30 \%$ do orçamento das universidades, de acordo com o memorando circular da instituição objeto de estudo, divulgado no ano de 2019 , os recursos destinados a assistência estudantil (PNAES), não tiveram seus valores bloqueados na ação orçamentária, contudo tiveram valores contingenciados deduzidos da ação de Funcionamento, a qual atende prioritariamente as unidades acadêmicas e as despesas essenciais de toda a Universidade. Desta maneira, mesmo com os impasses externos, a proposta de escalonamento situa-se como passível de implementação.

\section{Referências}

Abreu, E. M. C. de (2014). Avaliação da implementação da política de assistência ao estudante no contexto do plano de expansão da educação profissional e tecnológica no Maranhão. Revista de Políticas Públicas. 17(1), 59-68. https://doi.org/10.18764/21782865.v17n1p59-68

Andifes. (2019). V Pesquisa Nacional de Perfil Socioeconômico e Cultural dos (a) Graduandos (as) das IFES - 2018. Brasília: FONAPRACE. http://www.andifes.org.br/wpcontent/uploads/2019/05/V-Pesquisa-Nacional-de-Perfil-Socioecon\%C3\%B4mico-eCultural-dos-as-Graduandos-as-das-IFES-2018.pdf.

Araújo, C. B. Z. M. de (2013). Políticas públicas de permanência na educação superior brasileira nos anos 2000. 36 Reunião Nacional da ANPED. Sistema Nacional de Educação e Participação Popular: Desafios para as Políticas Educacionais. Goiânia/GO. ANPEd - Associação Nacional de Pós-Graduação e Pesquisa em Educação. http://36reuniao.anped.org.br/pdfs_trabalhos_aprovados/gt11_trabalhos_pdfs/gt11_3 415_texto.pdf.

Araújo, M. A. D. de, \& Pinheiro, H. D. (2010). Reforma gerencial do Estado e rebatimentos no sistema educacional: um exame do REUNI. Ensaio: Avaliação e Políticas Públicas em Educação. 18(69), 647-668. https://doi.org/10.1590/S0104-40362010000400002

Assis, A. C. L. de, Sanabio, M. T., Magaldi, C. A., \& Machado, C. S. (2013). As políticas de assistência estudantil: experiências comparadas em universidades públicas brasileiras. Revista Gestão Universitária na América Latina - GUAL. 6(4), 125-146. https://doi.org/10.5007/1983-4535.2013v6n4p125

Back, L. B. (2018). Assistência estudantil: da formalização aos desafios na consolidação do direito. Revista Educação Online. 30, 32-52. 
Cintra, R. F., Souza, G. V., Fava, H. L. (2020). Cavalo 'dado' se olha os dentes sim! Proposta de

Betzek, S. B. F. (2015). Avaliação do Programa Nacional de Assistência Estudantil - PNAES na UTFPR Câmpus Medianeira. Dissertação (Mestrado em Educação). Marília: Universidade Estadual Paulista.

Bordim, C. F., Baggio, D. K., Cintra, R. F., \& Ribeiro, I. (2019). Desempenho acadêmico e moradia estudantil: variáveis que afetam(?) os estudantes da UFGD. Colóquio Internacional de Gestão Universitária (CIGU). 1-16. Florianópolis.

Borges, M. C., \& Aquino, O. F. (2012). Educação Superior no Brasil e as políticas de expansão de vagas do Reuni: avanços e controvérsias. Educação: Teoria e Prática. 22(39). 22.

Brasil (1988). Constituição da República Federativa do Brasil. Brasília: Senado Federal.

Brasil (1996). Lei $n^{\circ}$ 9.394, de 20 de dezembro de 1996. Estabelece as diretrizes e bases da educação nacional. Brasília-DF <http://www.planalto.gov.br/ccivil_03/leis/I9394.htm

Brasil (2007). Decreto $n^{\circ}$ 6.096, de 24 de abril de 2007. Brasília-DF. http://www.planalto.gov.br/ccivil_03/_Ato2007-2010/2007/Decreto/D6096.htm

Brasil (2010). Decreto $n^{\circ} 7.234$, de 19 de julho de 2010. Brasília-DF. http://www.planalto.gov.br/ccivil_03/_ato2007-2010/2010/decreto/d7234.htm

Brito, A. C. T. da C., Costa, A. K. T. da, \& Almeida, V. L. de (2019) Gestão universitária: políticas comparadas de monitoramento do programa bolsa permanência em universidades federais brasileiras. Revista Ibero-Americana de Estudos em Educação. 14(3), 1862-1875. https://doi.org/10.21723/riaee.v14iesp.3.13036

Catani, A. M., Hey, A. P., \& Gilioli, R. de S. P. (2006). PROUNI: democratização do acesso às Instituições de Ensino Superior? Educar em Revista. 28, 125-140. https://doi.org/10.1590/S0104-40602006000200009

Cintra, R. F., Ribeiro, I., \& Costa, B. K. (2018). Reflexo da Moradia Estudantil no Índice de Desempenho Acadêmico: um Estudo Quantitativo na Universidade Federal da Grande Dourados. XLII Encontro da Associação Nacional dos Programas de Pós-Graduação e Pesquisa em Administração. 1-14. Curitiba.

De León, J. C. V. (2006). Vulnerability: A conceptual and methodological review. Germany: UNU-EHS.

Del Giúdice, J. Z. A. (2013). Programa de Assistência Estudantil da Universidade Federal de Viçosa/MG: Repercussões nos Indicadores Acadêmicos e na Vida Pessoal, Familiar e Social dos Beneficiários. Dissertação (mestrado). Viçosa: Universidade Federal de Viçosa.

Del Giúdice, J. Z., Loreto, M. das D. S., \& Azevedo, D. S. (2014). Vulnerabilidade social como critério utilizado na política de assistência estudantil: uma análise conceitual e empírica. Serviço Social em Revista. 17(1), 27-45.

Fava, H. L. \& Cintra, R. F. (2020). Indicadores na Assistência Estudantil: análise nas universidades federais brasileiras. XXIII Seminários em Administração. São Paulo.

Garrido, E. N. (2012). Assistência estudantil: sua importância, atores envolvidos e panorama atual. Seminário Universidade Sociedade. Semana KIRIMURÊ. Bahia. http://www.institutokirimure.pro.br/wp-content/uploads/2012/11/GARRIDO_E.pdf

ISDR. (2004). Living with Risk: A global review of disaster reduction initiatives. New York and Geneva: United Nations. https://www.unisdr.org/files/657_lwr1.pdf

Lima, W. A. S. (2017). Permanecer no Ensino Superior, eis a questão: estratégias de implementação efetiva de políticas públicas de Assistência Estudantil. Dissertação (Mestrado Profissional em Administração). Salvador: Universidade Federal da Bahia.

Martins, P. F. de M., SILVA, E. G. da, \& Mauricio, N. M. M. (2019). A história da assistência estudantil no ensino superior brasileiro: programa nacional de assistência estudantil e o 
aumento das classes "D" e "E" nas universidades federais. Revista Observatório. 5(6), 886-911. https://doi.org/10.20873/uft.2447-4266.2019v5n6p886

MEC (2013). Portaria $n^{\circ} 389$, de 9 de maio de 2013. Brasília-DF. https://www.in.gov.br/materia/-/asset_publisher/Kujrw0TZC2Mb/content/id/30550825

Oliveira, E. G. de, \& Silva, E. V. (2018). Convergências e dissonâncias dos programas PNAES e Bolsa-permanência e a Lei de Cotas. Revista Labor. 1(19), 5-14.

Oliveira, J. R. de (2017). Acesso e permanência na educação superior-os percalços dos alunos em situação de vulnerabilidade socioeconômica no curso de Pedagogia - área de aprofundamento em Educação do Campo - UFPB. Trabalho de conclusão de curso de graduação. João Pessoa: Universidade Federal da Paraíba.

Paula, M. de F. C. de (2017). Políticas de democratização da educação superior brasileira: limites e desafios para a próxima década. Avaliação: Revista da Avaliação da Educação Superior (Campinas). 22(2), 301-315. https://doi.org/10.1590/s141440772017000200002

Pereira, L. T., \& Almeida, M. de S. (2015). A definição do perfil de vulnerabilidade para acesso à política de permanência no ensino superior. Revista Gestão Universitária na América Latina - GUAL. 132-154. https://doi.org/10.5007/1983-4535.2015v8n1p132

Ristoff, D. (2014). O novo perfil do campus brasileiro: uma análise do perfil socioeconômico do estudante de graduação. Avaliação: Revista da Avaliação da Educação Superior (Campinas). 19(3), 723-747. https://doi.org/10.1590/S1414-40772014000300010

Santiago, S. N. (2014). A política de assistência estudantil no governo Lula: 2003 a 2010. Dissertação (mestrado). Belém: Universidade Federal do Pará.

Saraiva, L. A. S., \& Nunes, A. de S. (2011). A efetividade de programas sociais de acesso à educação superior: o caso do ProUni. Revista de Administração Pública. 45(4), 941-964. https://doi.org/10.1590/S0034-76122011000400003

Sobrinho, J. D. (2010). Democratização, qualidade e crise da educação superior: faces da exclusão e limites da inclusão. Educação \& Sociedade. 31(113), 1223-1245. https://doi.org/10.1590/S0101-73302010000400010

Souza, G. V. de, \& Cintra, R. F. (2020). Política Pública de Assistência Estudantil no Brasil: análise da última década (2011-2019). Encontro da Associação Nacional dos Programas de Pós-Graduação e Pesquisa em Administração. Porto Alegre. 